University of Texas Rio Grande Valley

ScholarWorks @ UTRGV

$12-2020$

\title{
An Association Between Perceived Social Support and Posttraumatic Stress Symptom Severity Among Women With Lifetime Sexual Victimization: The Serial Mediating Role of Resilience and Coping
}

Michiyo Hirai

The University of Texas Rio Grande Valley, michiyo.hirai@utrgv.edu

Ruby Charak

The University of Texas Rio Grande Valley, ruby.charak@utrgv.edu

Laura D. Seligman

The University of Texas Rio Grande Valley

Joseph D. Hovey

The University of Texas Rio Grande Valley

John M. Ruiz

Follow this and additional works at: https://scholarworks.utrgv.edu/psy_fac

PPratodabe fantanditionglarathorss, Counseling Psychology Commons, and the Women's Studies Commons

\section{Recommended Citation}

Hirai, M., Charak, R., Seligman, L. D., Hovey, J. D., Ruiz, J., \& Smith, T. (2020). An Association Between Perceived Social Support and Posttraumatic Stress Symptom Severity Among Women With Lifetime Sexual Victimization: The Serial Mediating Role of Resilience and Coping. Violence Against Women. https://doi.org/10.1177/1077801219892645

This Article is brought to you for free and open access by the College of Liberal Arts at ScholarWorks @ UTRGV. It has been accepted for inclusion in Psychological Science Faculty Publications and Presentations by an authorized administrator of ScholarWorks @ UTRGV. For more information, please contact justin.white@utrgv.edu, william.flores01@utrgv.edu. 


\section{Authors}

Michiyo Hirai, Ruby Charak, Laura D. Seligman, Joseph D. Hovey, John M. Ruiz, and Timothy W. Smith 
Running head: SOCIAL SUPPORT, RESILIENCE, COPING, \& SEXUAL TRAUMA

\title{
AN ASSOCIATION BETWEEN PERCEIVED SOCIAL SUPPORT AND POSTTRAUMATIC STRESS SYMPTOM SEVERITY AMONG WOMEN WITH LIFETIME SEXUAL VICTIMIZATION: THE SERIAL MEDIATING ROLE OF RESILIENCE AND COPING
}

\author{
Michiyo Hirai \\ University of Texas Rio Grande Valley; michiyo.hirai@utrgve.edu \\ Ruby Charak \\ University of Texas Rio Grande Valley; ruby.charak@utrgve.edu \\ Laura D. Seligman \\ University of Texas Rio Grande Valley; laura.seligman@utrgve.edu \\ Joseph D. Hovey \\ University of Texas Rio Grande Valley; joseph.hovey@utrgve.edu \\ John M. Ruiz \\ University of Arizona; johnruiz@email.arizona.edu \\ $\&$ \\ Timothy W. Smith \\ University of Utah; tim.smith@psych.utah.edu
}

Corresponding Author:

Michiyo Hirai, Ph.D.

Department of Psychological Science

University of Texas Rio Grande Valley

$1201 \mathrm{~W}$. University Drive

Edinburg, TX 78539

E-mail: michiyo.hirai@utrgve.edu; Phone: (956) 665-2638; Fax: (956) 665-3333 


\begin{abstract}
This study examined the association between perceived social support and severity of posttraumatic stress symptoms, serially mediated by resilience and coping among women exposed to different patterns of sexual victimization experiences: childhood sexual abuse (CSA) only, adult sexual assault (ASA) only, and sexual revictimization (SR). 255 sexually victimized women recruited from four US universities completed self-report measures online. 112 participants reported provisionally diagnosable levels of symptoms of PTSD. The proposed model was largely supported in the CSA only group and the SR group. Different patterns of mediational effects were found across the three groups. Clinical and theoretical implications are discussed.
\end{abstract}

Keywords. sexual victimization, perceived social support, resilience, coping, trauma 
An Association between Perceived Social Support and Posttraumatic Stress Symptom Severity among Women with Lifetime Sexual Victimization: The Serial Mediating Role of Resilience and Coping

Prior research suggests that between $6.6 \%$ and $21 \%$ of women have experienced sexual victimization (e.g., Bagwell-Gray, Messing, \& Baldwin-White, 2015; Carey, Durney, Shepardson, \& Carey, 2015; Conley et al., 2017; Hines, Armstrong, Reed, \& Cameron, 2012). Reports on a national sample found that when reporting lifetime traumatic experiences women frequently endorsed sexual victimization as the most distressing traumatic event (Smith, Summers, Dillon, \& Cougle, 2016). Survivors of sexual assault may experience a myriad of negative psychological consequences, including posttraumatic stress disorder (PTSD) (e.g., Scott et al., 2018). A recent meta-analytic study reported sexual victimization as one of the significant risk factors associated with traumatic stress and related conditions (Dworkin, Menon, Bystrynski, \& Allen, 2017). Sexual victimization has been found to be associated with more PTSD symptoms and longer duration of symptoms compared to other forms of traumatic events (Smith et al., 2016). Understanding the processes that lead to negative outcomes following sexual victimization is important as it informs prevention and intervention strategies. In this regard, past research highlights the importance of perceived social support (e.g., Schumm, Briggs-Phillips, \& Hobfoll, 2006; Steine et al., 2017), resilience (e.g., van der Walt, Suliman, Martin, Lammers, \& Seedat, 2014; Wisco et al., 2014), and coping (e.g., Leiner, Kearns, Jackson, Astin, \& Rothbaum, 2012; Ullman, Townsend, Filipas, \& Starzynski, 2007) in understanding reactions to sexual victimization. Yet, the interplay of these constructs has not been investigated. Thus, the current study tested a model describing the associations among perceived social support, resilience, and coping, predicting posttraumatic stress symptom (PTS) severity in women exposed to sexual 
victimization.

\section{Associations between Perceived Social Support and Traumatic Stress Symptom Severity}

A variety of theories exist to explain and operationalize the role of social support in consequences of traumatic life events (e.g., Norris \& Kaniasty, 1996; see Wagner, Monson, \& Hart, 2016 for review), suggesting direct, moderating, and mediating roles of social support. One conceptualization of social support classifies it into perceived social support and received social support. Perceived social support is the individual's perception that helping behavior is available, while received social support is helping behavior that was provided to the individual (e.g., Norris \& Kaniasty, 1996). Between the two types of social support, the importance of perceived social support in relation to sexual victimization has been addressed (e.g., Steine et al., 2017). The relationship between higher perceived social support and psychological wellbeing can be explained by two models: a social causation model and a social selection mode of social support. Original social causation theory and social selection theory focused on the relationship between low SES and risk of psychological disorders (Johnson, Cohen, Dohrenwend, Link, \& Brook, 1999). The social causation model of perceived social support suggests higher perceived social support lead to less psychological distress, while the social selection model asserts psychological symptoms lower one's perceived social support levels (e.g., Kaniasty \& Norris, 2008). Between the two directional theories, evidence exists to support the social causation model of perceived social support applicable to various traumatic events, including sexual victimization. Two metaanalytic studies reported that lack of perceived social support was a significant predictor of PTS severity (a weighted effect of .40 in Brewin et al., 2000 and .28 in Ozer et al., 2003). In studies focusing on sexual victimization, higher perceived social support predicted lower levels of PTS among college women who were sexually victimized during adolescence or adulthood (Littleton, 
2010), in women with childhood sexual abuse (Evans et al., 2013; Steine et al., 2017), and in women who experienced both childhood sexual abuse and adult sexual assault (Schumm et al., 2006). Although not all studies support the relationship (Wilson \& Scarpa, 2014), a large proportion of research supports higher perceived social support contributing to lower detrimental effects of sexual victimization.

\section{$\underline{\text { Associations between Resilience and Posttraumatic Stress Symptoms }}$}

Another psychological variable that may influence consequences of sexual victimization is resilience. According to Carver (1998), individuals experience a decline in physical or psychological homeostasis in response to adversity, which leads to four potential consequences: succumbing, survival with impairment, resilience, and thriving. Resilience explains the individual's "homeostatic return to a prior condition" after an adverse event. Individuals with strong resilience likely bounce back to their prior psychological functioning and thus experience less psychological distress in response to a traumatic experience. Several recent studies reported higher resilience associated with less negative consequences of sexual victimization. For example, higher resilience has been related to a lower likelihood of a provisional diagnosis of PTSD in veterans with a sexual abuse history in adulthood (Wisco et al., 2014) and to lower PTS severity in adult female survivors of rape (van der Walt et al., 2014). These theoretical and empirical reports suggest that levels of resilience that sexually victimized women display in response to the stressful experiences are important determinants of post-trauma outcomes.

\section{$\underline{\text { Associations between Coping and Trauma Symptom Severity }}$}

Coping has also been found to contribute to the psychological outcomes among sexually traumatized women (e.g., Bedard-Gilligan et al., 2015; Leiner et al., 2012; Ullman et al., 2007). According to the approach-avoidance model of coping (Roth \& Cohen, 1986), coping with stress 
can be oriented toward approach and/or avoidance. Approach-oriented coping includes adaptive strategies in which an individual makes changes in a situation or takes appropriate actions to prevent further stress. When individuals use avoidance-oriented coping, they may avoid, reject, deny, ignore, or seek distractions from the stressor and its consequences, and/or may engage in other maladaptive strategies. Although the model suggests that the two orientations are not mutually exclusive and have costs and benefits, the avoidance orientation specifically may result in potential negative consequences, including emotional numbness, intrusions of threatening information, and avoidance of trauma-related stimuli, all of which correspond to symptoms of PTSD. Avoidance may prevent amelioration from consequences of traumatic experiences. According to emotional processing theory (Foa \& Kozak, 1996), avoidance behavior interferes with activation of fear - an essential factor for successful recover. A cognitive model of PTSD (Ehlers \& Clark, 2000) suggests that strong negative appraisals of the trauma or trauma consequences and poor integration of the trauma memory into the autobiographical memory lead to persistent symptoms of PTSD, and avoidance contributes to both processes. Using avoidanceoriented coping after sexual victimization likely persists or exacerbates distress.

Empirical evidence supports the role of avoidance-oriented coping in consequences of sexual victimization. For example, among female victims of rape with a PTSD diagnosis, higher levels of PTSD symptoms were predicted by greater pretreatment avoidance coping levels (Leiner et al., 2012). Cross-sectional studies also reported that avoidance coping was associated with greater severity of PTS in sexually victimized women (Bedard-Gilligan et al., 2014; Ullman et al., 2007). In addition, a meta-analytic study found an association between avoidance coping and PTS severity among victims of interpersonal violence, including sexual victimization (Littleton, Horseley, John, \& Nelson, 2007). However, the role of approach-oriented, adaptive 
coping on recovery from sexual victimization is mixed. For example, Gutner et al. (2006) found that increases in adaptive coping, such as cognitive restructuring shortly after traumatic experiences, were related to less severe PTS in female victims of physical and sexual assault. By contrast, Cole and Lynn (2010) found evidence for a positive association between adaptive coping and greater PTS severity in female survivors of sexual victimization. In addition, the meta-analytic study (Litteleton et al., 2007) found that approach-oriented coping was positively related to severity of PTS. Together, the existing literature suggests negative effects of avoidance-oriented, maladaptive coping on PTS severity in response to sexual victimization. However, the role of approach-oriented adaptive coping in PTS severity is less clear.

\section{Serial Mediation Paths from Perceived Social Support to Resilience followed by Coping}

The above literature suggests that perceived social support, resilience, and coping independently predict severity of PTS associated with sexual victimization. In addition to these direct predictive roles, complex relationships among perceived social support, resilience, and coping may exist. First, the path from perceived social support to resilience is assumed. Although one conceptualization of resilience proposes resilience as a dispositional construct, more recent theories suggest resilience itself as a dynamic, changeable process (see Luthar. Cicchetti, \& Becker, 2000 for review). For example, Connor and Davidson (2003) proposed that one might experience a disruption of a biopsychospiritual balance in response to stressors and the disruption then may lead to an opportunity for increased, same, or lower resilience. Evidence exists to propose perceived social support as a factor that influences levels of resilience in individuals with sexual victimization experiences. A review study on childhood sexual victimization identified social support including perceived social support as one of the factors that may promote resilience (Marriott, Hamilton-Giachritsis \& Harrop, 2014). While not 
targeting sexual victimization, perceived social support predicted resilience in individuals after the September 11 attack (Bonanno, Galea, Bucciarelli, \& Vlahob, 2007). In addition, a study of female victims of intimate partner violence found evidence for a positive relationship between higher perceived social support and higher resilience (Jose \& Novaco, 2016). The next path is from resilience to coping. Theoretically, resilience has been linked with one's coping ability (Connor \& Davison, 2003; Greene, Galambos, \& Lee, 2003) such that individuals exposed to a traumatic event demonstrating higher resilience would be expected to engage in adaptive coping, such as approach-oriented strategies. On the other hand, individuals with lower resilience may apply maladaptive coping, such as, avoidance-oriented strategies. Overall, the above theoretical formulations and empirical findings suggest the presence of the serial path from perceived social support to resilience followed by coping when considering the relationships among these variables in women with exposure to sexual victimization.

\section{Direct Mediating Roles of Resilience and Coping}

By applying the original idea of social causation theory described above, perceived social support is expected to be an antecedent of one's resources, such as resilience and coping. There is some evidence to support the mediating role of resilience between perceived social support and PTS severity. While not targeting sexual victimization, a study identified resilience as a mediator of the association between perceived social support and PTS levels in women with exposure to war (Besser, Weinberg, Zeigler-Hill, \& Naria, 2017) and in cancer survivors (Dong et al., 2017). Further, empirical evidence suggests a path from perceived social support to coping. Specifically, higher perceived social support was found to be related to higher adaptive coping in women exposed to assault including sexual victimization (Stevens-Watkins, Sharma, Knighton, Oser, \& Leukefeld, 2014) and to less maladaptive and more adaptive coping in a 
college sample including sexually victimized women (Haden, Scarpa, Jones, \& Ollendick, 2007). These findings in conjunction with the predictive role of coping for PTS severity suggest the presence of the mediating role of coping in the relationship between perceived social support and PTS severity.

\section{$\underline{\text { An Integrated Model Applied to Different Patterns of Sexual Victimization }}$}

The current study proposed a model that perceived social support, resilience, and coping have direct effects on PTS severity, and resilience and coping serially mediate the relationship between perceived social support and PTS severity (Figure 1).

Some evidence suggests PTS severity and its relationships with the psychosocial factors may be complex among different patterns of lifetime sexual victimization, namely, adult sexual assault only (ASA), childhood sexual abuse only (CSA), and sexual revictimization (SR; i.e., CSA and ASA). Regarding PTS severity, previous research suggests that SR survivors are more likely than CSA only or ASA only survivors to develop severe PTS or PTSD. For example, a review study (Classen, Palesh, \& Aggarwal, 2005) as well as an empirical study (Schumm et al., 2006) reported that SR was a stronger risk factor than CSA only or ASA only for severe PTS or PTSD. With regard to perceived social support, Schumm et al. (2006) reported the lowest levels of perceived social support in SR women, followed by women with CSA only. While not solely resilience, Walsh, Blaustein, Knight, Spinazzola, and van der Kolk (2007) found that selfefficacy and internal locus of control, which were considered internal resilience factors, were higher in CSA only victims than in SR victims. Neither resilience nor coping has been addressed and compared across the three groups. Essentially, past studies that addressed perceived social support, resilience, or coping in relation to sexual victimization often targeted victimization across a single developmental phase (e.g., adulthood only, childhood only). Unknown is whether 
differential sexual victimization pathways throughout the developmental stages might produce differential cumulative effects on the relationship between PTS severity associated with sexual victimization and the psychosocial factors. More comprehensive investigations in the association among the variables in women exposed to different patterns of sexual victimization are essential.

The current study tested the serial mediation model (Figure 1) in women exposed to CSA only, ASA only, or SR, separately. The study hypothesized: (1) higher perceived social support, higher resilience, higher adaptive coping, and lower maladaptive coping would be related to lower levels of PTS; and (2) The relationship between perceived social support and PTS severity would be serially mediated by resilience and coping. These relationships were assumed to be found across the three groups. As a first step in testing these relationships we examined the model in a convenience sample of female college students with a history of sexual victimization. If evidence to support the model is detected it would support more focused investigations including longitudinal studies in at-risk populations.

Figure 1 about here

\section{METHOD}

\section{Participants}

A total of 3,113 students from four geographically diverse public universities participated in an online study. Among these participants, 2,235 female participants completed the target questionnaires for the current study. A total of 321 women (14.4\%) reported sexual victimization ${ }^{1}$. Among the 321 women, 267 reported sexual victimization as a most traumatic life event and rated their symptoms for experiences of sexual victimization. Among the 267 participants, 12 
had missing data and data imputation was not performed. Thus, data from 255 participants were analyzed. The remaining 54 participants reported another event as a most stressful life event for which they rated their symptoms, and thus were not included in the current analyses. Among the 255 participants, 106 reported ASA only and ASA as a most stressful life event, 97 reported CSA only and CSA as a most stressful life event, and 52 reported both CAS and ASA and either CSA or ASA as a most stressful life event. The mean age was 20.9 years old $(S D=3.7)$, ranging from 18 to 41 years old. There were 109 non-Hispanic White, 106 Hispanic, 21 African American, 9 Asian American, 1 Native American, 1 Pacific Islander, and 8 mixed race women.

\section{$\underline{\text { Measures }}$}

A demographic questionnaire asked participants to report age, sex, and ethnicity. The Stressful Experience Checklist (SEC: Hirai, Skidmore, Clum, \& Dolma, 2012) presented 11 specific traumatic or stressful events that may occur in one's lifetime. The items included: physical assault as an adult, sexual assault as an adult, disaster (e.g., hurricane, etc.), accident, childhood physical abuse, childhood sexual abuse, and other. Participants were able to report an event that was not listed. Participants indicated all events they had experienced and selected the one that they considered to be the most stressful for them and reported the time elapsed since the most stressful event happened ${ }^{2}$.

The PTSD Checklist-DSM-5 version (PCL-5; Weathers, Keane, Palmieri, Marx, \& Schnurr, 2013) is a 20-item self-report questionnaire that assesses posttraumatic stress symptom severity, corresponding to DSM-5 criteria. The respondent rated each item regarding her sexual victimization experience based on a 5-point Likert scale where 0 is "not at all" and 4 is "extremely." It can be used to establish a provisional PTSD diagnosis (Blevins, Weathers, Davis, Witte, \& Domino, 2015) based on the criteria (Weathers et al., 2013). A strong internal 
consistency reliability estimate for the total scale (alpha $=.94$ ) was reported (Blevins et al., 2015). Cronbach's alphas for the total scale for the present groups ranged from .94 to .95 .

The Social Provisions Scale (SPS; Cutrona \& Russell, 1987) is a 24-item questionnaire, assessing perceived availability of social support functions. Items are rated on a 4-point Likert scale ranging from 1 (strongly disagree) to 4 (strongly agree). A high internal consistency reliability estimate of the total scale (alpha $=.92)$ was reported (Cutrona \& Russell, 1987). Cronbach's alphas for the total scale in the current groups ranged from .92 to .94 . The SPS has been used in studies targeting sexual victimization (e.g., Schumm, et al., 2006).

The Connor-Davidson Resiliency Scale (CD-RISC; Connor \& Davidson, 2003) is a 25item self-report questionnaire, assessing resilience. Items are rated on a 5-point Likert scale (0-4) where 0 is "not true at all" and 4 is "true nearly all of the time." A higher score indicates higher resiliency. Cronbach's alpha for a general population sample was .89 (Connor \& Davidson, 2003). Cronbach's alphas for the present groups ranged from .93 to $.94^{3}$. The CD-RISC has been used in studies targeting sexual victimization (e.g., van der Walt et al., 2014).

The Brief Coping (BC; Carver, 1997) is a 28-item self-report, evaluating one's coping responses. The $\mathrm{BC}$ produces 14 subscales. The $\mathrm{BC}$ was used to assess ongoing coping to sexual victimization experience the respondent reported since it had occurred. Items are rated on a 4point Likert scale (1-4) where 1 is "I haven't been doing this at all" and 4 is "I've been doing this a lot." The current study used two broad scales, maladaptive coping and adaptive coping. The maladaptive coping scale was a composite score of the denial, disengagement, self-blame, and substance use, assessing avoidant-oriented coping strategies. This composite scale has been used in recent studies with sexual assault victims (e.g., Ullman \& Peter-Hagene, 2014). Cronbach's alpha for sexual assault victims was .81(Ullman \& Peter-Hagene, 2014). The adaptive coping 
scale consisted of active coping, positive reframing, planning, and acceptance subscales, assessing approach-oriented coping strategies. The emotional and instrumental support subscales were not included in the adaptive coping scale to reduce content overlap between the SPS and this scale. The present groups showed alphas for the maladaptive coping scale ranging from .77 to .85 and for the adaptive coping scale ranging from .82 to .86 .

\section{Procedure}

The current study was part of a larger online assessment of psychological and behavioral experiences that was approved by the institutional review boards of the four universities where the study took place. Individuals who read the online consent form and agreed to participate completed the online questionnaires, anonymously. Participants received extra course credit as compensation.

\section{$\underline{\text { Analysis Plan }}$}

To compare the levels of the examined variables by group, ANOVAs were conducted with SPSS Version 24. To test the mediation models, PROCESS (Hayes, 2012) was used. To obtain 95\% bias-corrected confidence intervals for the mediation models, 5,000 bootstrap estimates were used.

\section{RESULTS}

Means and standard deviations of the variables of interest and group comparison results are presented in Table 1. No significant group differences were found for levels of perceived social support, resilience, or adaptive coping. Maladaptive coping scores and PTS severity scores differed significantly across the groups. Post-hoc analyses revealed that the ASA only and SR groups reported significantly higher levels of maladaptive coping and PTS severity than the CSA only group. Based on the PCL-5 criteria (Weathers et al., 2013), 47\% $(n=50)$ in the ASA only 
group, 34\% ( $n=33)$ in the CSA only group, and 56\% $(n=29)$ in the SR group reported symptoms consistent with a provisional diagnosis of PTSD. A significant group difference for diagnostic status was found $\left(\chi^{2}(1)=6.59, p<.05\right)$, with the SR group evidencing a significantly higher rate of provisional diagnosis of PTSD compared to the CSA only group. Because the sample consisted of a large proportion of Hispanics, comparisons between Hispanic and nonHispanic groups on the variables of interest were performed by group. Ethnicity effects on the variables of interest were not significant $(.53<p<.88)$. In addition, location effects on the variable were not significant $(.13<p<.89)$.

Table 1 about here

Table 2 presents correlations among the variables of interest. Perceived social support and resilience were significantly negatively correlated with PTS severity, and both adaptive and maladaptive coping were significantly positively correlated with PTS severity within all three groups. Resilience was significantly negatively correlated with maladaptive coping across the three groups. Resilience was significantly positively correlated with adaptive coping only in the CSA only group. Perceived social support had no correlation with adaptive coping in any group.

Table 2 about here

Although the correlations suggested that the mediating role of adaptive coping would not be found for the ASA and SR groups, the model was examined to demonstrate group differences. Results for the proposed model (Figure 1) are presented in Table 3 and illustrated in Figures 2 
and 3. For the ASA only group, the relationship between perceived social support and PTS severity was fully mediated by maladaptive coping. Contrary to the hypothesis, resilience was not found as a mediator. When adaptive coping was tested in the model, no mediation effects were found. For the CSA only group, the relationship between perceived social support and PTS severity was fully mediated by resilience and maladaptive coping, serially. When the role of adaptive coping was tested, the relationship between perceived social support and PTS severity was partially mediated by resilience and adaptive coping serially and also by resilience alone. The direct effect of perceived social support on PTS severity was still significant. For the SR group, the relationship between perceived social support and PTS severity was fully mediated by resilience and maladaptive coping, serially and also by resilience alone. When adaptive coping was tested in the model, resilience fully mediated the relationship between perceived social support and PTS severity. Adaptive coping was not a significant mediator for this group.

Table 3 about here

Figure 2 about here

\section{DISCUSSION}

The present study examined the association between perceived social support and PTS severity serially mediated by resilience and coping in women exposed to sexual victimization. The model was examined separately for different patterns of sexual victimization experiences: CSA only, ASA only, and SR. As hypothesized, higher perceived social support, higher 
resilience, and lower maladaptive coping were correlated with lower PTS severity, which are consistent with prior studies that tested these roles in sexually victimized women mainly across a single developmental phase (e.g., ASA only, CSA only) (e.g., Bedard-Gilligan et al., 2014; Evans, et al., 2013; Ullman et al., 2007; van der Walt et al., 2014), and with the theories (e.g., Conner \& Davidson, 2003; Kaniasty \& Norris, 2008; Foa \& Kozak, 1986; Ehlers \& Clark, 2000). For example, the identified significant relationship between lower avoidance-oriented coping and less severe PTS levels was consistent with the theoretical formulations for the relationship (Foa \& Kozak, 1986; Ehlers \& Clark, 2000), suggesting that avoidance-oriented maladaptive coping is a strong contributor to PTS in sexually victimized women. The result that these direct relationships were found in the three groups is important. Specifically, the direct predictive role of these variables in PTS severity may be uniform in women exposed to different patterns of sexual victimization, suggesting that perceived social support, resilience, and coping altogether should be assessed in relation to PTS regardless of patterns of sexual victimization women have experienced. Contrary to the hypothesis, higher adaptive coping was correlated with higher PTS severity for the three groups. As stated above, previous studies reported inconsistent results regarding the effects of adaptive coping on recovery (Cole \& Lynn, 2010; Gutner et al., 2006). A possibility is that different adaptive coping strategies (e.g., behavioral, cognitive) may have differential relationships with PTS severity. Further, symptomatic participants at the time of the assessment may have applied both adaptive and maladaptive coping to handle distress. Longitudinal investigations in specific adaptive coping strategies in relation to PTS severity across different victimization patterns are warranted.

The hypothesis that resilience and coping serially mediate the association between perceived social support and PTS severity was partially supported (Figure 2). First, the proposed 
serial mediation model with maladaptive coping was fully supported only by the CSA only and SR groups (i.e., CSA was experienced). This finding suggests that the path from perceived social support to resilience then to maladaptive coping may have been developed longitudinally over the course of development. Interestingly, resilience alone did not mediate the relationship for any of the groups when maladaptive coping was considered as a second mediator further in the chain of constructs. These findings support the importance of assessing the sequential mediating roles of resilience and maladaptive coping, rather than focusing only on resilience as an isolated mediator, in the relationship between perceived social support and PTS applying the model particularly to women with experiences of CSA.

Avoidance-oriented maladaptive coping without the effects of resilience was then found to play a significant mediating role for the three groups (Figure 2). These results are attributed to the significant correlations between higher perceived social support and less maladaptive coping in the three groups, which was consistent with the past findings (e.g., Haden et al., 2007). The significant mediation path in the three groups suggests that unlike the path to resilience, the path from perceived social support to maladaptive coping may be quickly established after the traumatic event and maintained longitudinally. It is speculated that the immediate reactions sexually traumatized women choose in response to their traumas are avoidance-oriented maladaptive coping, such as avoidance and denial, which can then be maintained longitudinally. For such cases, higher resilience and higher perceived social support could be crucial factors that reduce the frequency and intensity of applying such maladaptive coping strategies. Particularly attempting to improve perceived social support could produce immediate and longitudinal positive effects on reducing maladaptive coping, which could in turn contribute to reducing PTS, regardless of patterns of sexual victimization. 
The serial mediation model with approach-oriented adaptive coping was supported only by the CSA only group (Figure 3). The ASA only and SR groups did not show a significant path from resilience to adaptive coping. Further, unlike maladaptive coping, adaptive coping itself did not mediate the relationship between perceived social support and PTS in any of the groups. These results are attributed to the lack of a significant bivariate relationship between adaptive coping and perceived social support or resilience across the three groups, except the CSA only group producing a significant correlation between resilience and adaptive coping. These nonsignificant correlations were contrary to what previous research suggested (e.g., Connor \& Davison, 2003; Stevens-Watkins et al., 2014). Approach-oriented adaptive coping strategies, such as engaging in appropriate behavioral, cognitive, and/or emotional actions to prevent further stress, may be demanding, and thus, resilience or perceived social support itself may not be powerful enough to increase levels of adaptive coping strategies in sexually victimized women.

Regarding PTS severity, the ASA only and SR groups reported significantly more severe PTS than the CSA only group (Table 1). Further, the SR group included a significantly larger proportion of victims with provisionally diagnosable PTSD than the CSA only. These findings are largely consistent with the past findings reporting high risk of PTSD in SR individuals (e.g., Classsen et al., 2005; Schumm et al., 2006). Unlike the past studies, the current findings report no significant difference in PTS severity between ASA only and SR groups, although the latter had a higher mean score. The small sample size of the SR group might explain the nonsignificant group difference.

Overall, the current study found positive effects of perceived social support and resilience and negative effects of maladaptive coping on PTS severity in the CSA only, ASA only, and SR groups. Differential effects of the mediators on the relationship between perceived social support 
and PTS severity were also found for different patterns of sexual victimization experiences. Although the cross-sectional nature of the study design does not allow causal claims, the findings suggest several possible clinical implications. Promoting perceived social support and reducing maladaptive coping might augment effectiveness of interventions targeting PTS associated with sexual victimization, regardless of patterns of victimization experiences. Lack of treatment response might be attributed to lack of perceived social support, low levels of resilience, use of maladaptive coping, or any combination of these conditions. Further, when perceived social support, resilience, and coping are examined in relation to PTS severity in women exposed to sexual victimization, the sequential effects of the variables unique to different patterns of sexual victimization may be taken into account. Yet, because maladaptive coping is a mediator across the three groups, when lack of perceived social support is targeted as part of an augmenting element of interventions for PTS, changes in maladaptive coping response as part of recovery processes should be examined. As noted above, attempting to improve perceived social support in sexually traumatized women could produce immediate and longitudinal positive effects on improving resilience and reducing maladaptive coping, which could in turn contribute to improving PTS. In addition, when treating women with experiences of CSA, improvement in resilience levels, as a process indictor, should be monitored.

The fact that the three groups identified differential patterns of mediational effects is theoretically important. Specifically, existing and future theoretical models with any combinations of the currently targeted variables or with broader psychosocial variables may need to be separately tested across groups with differential victimization history. Such efforts will likely help fine-tune theoretical models suitable for individuals with specific victimization history. 
It should be noted that this study has several limitations. The current findings were from college students and thus have limited generalizability to community and clinical samples. Yet, $34-56 \%$ of the participants reported provisionally diagnosable levels of PTSD symptoms, which confirms that the current model is applicable at least to symptomatic women exposed to sexual victimization. The SR group had a small sample size, which might explain some non-significant effects found for the SR group. Further, the current sample consisted of only women. Moreover, given the correlational nature of the study design, causal claims are not warranted. As past studies suggest (e.g., Kaniasty \& Norris, 2008), both the social selection and the social causation models could be possible scenarios. In addition, sexual victimization history was assessed via a checklist, not by behaviorally-specific assessment instruments such as the Sexual Experiences Survey (Koss et al., 2007), and thus variability in sexual victimization experiences in relation to PTS and psychosocial experiences were unable to address. Future research should examine the model longitudinally in larger community and clinical samples with both men and women across different patterns of sexual victimization assessed by behavior-specific measures.

Despite the above limitations, the identification of resilience and coping as possible serial mediators of the relationship between perceived social support and PTS severity is an important contribution. The current model was soundly developed based on recent empirical findings as well as established theories of the relationships among perceived social support, resilience, coping, and PTS severity. Our findings indicate that different patterns of sexual victimization experiences may result in different mediation pathways across the above variables. Preventative efforts and interventions should take different roles of these variables among different sexual victimization experiences into consideration. 


\section{NOTES}

1. The prevalence of sexual victimization was within the range of prevalence rates of sexual victimization reported in recent studies with college student samples, ranging from $6.6 \%$ to 19.4\% (Carey et al., 2015; Conley et al., 2017; Hines et al., 2012; Littleton, 2010).

2. Within the ASA only group (ages ranged from 18 years old to 33 years old), the times since the event happened varied from 1 weeks to 9 years. Within the CSA only group (ages ranged from 18 years old to 41 years old), the times since the event happened varied from 3 years to 33 years. Among the RS group (ages ranged from 18 years old to 32 years old), the time since the most stressful event (either, CSA or ASA) varied from 2 weeks (ASA) to 25 years (CSA).

3. To examine whether perceived social support, coping, and resilience were three distinct constructs, an exploratory factor analysis with principal axis factoring was performed. The Direct Oblimin rotation was used. Eigenvalues were above 1.0 for the three extracted factors. All SPS items and all BC adaptive and maladaptive cope items were loaded onto their corresponding factors. Two CD-RISC items were loaded onto the SPS factor and the remaining CD-RISC items were loaded onto the factor forming resilience. Thus, total resilience scores were calculated without the two items. These alphas were for the resilience items without the two multi-loaded items. No change was made for the SPS and BC scales. 


\section{REFERENCES}

Bagwell-Gray, M. E., Messing, J. T., \& Baldwin-White, A. (2015). Intimate partner sexual violence: A review of terms, definitions, and prevalence. Trauma, Violence, \& Abuse, 16(3), 316-335. doi:10.1177/1524838014557290

Bedard-Gilligan, M., Cronce, J. M., Lehavot, K., Blayney, J. A., \& Kaysen, D. (2014). The relationship between assault and physical health complaints in a sample of female drinkers: Roles of avoidant coping and alcohol use. Journal of Interpersonal Violence, 29(8), 13591379. doi:10.1177/0886260513507139

Besser, A., Weinberg, M., Zeigler-Hill, V., \& Neria, Y. (2014). Acute symptoms of posttraumatic stress and dissociative experiences among female Israeli civilians exposed to war: The roles of intrapersonal and interpersonal sources of resilience. Journal of Clinical Psychology, 70, 1227-1239. doi:10.1002/jclp.22083

Blevins, C. A., Weathers, F. W., Davis, M. T., Witte, T. K., \& Domino, J. L. (2015). The posttraumatic stress disorder checklist for DSM-5 (PCL-5): Development and initial psychometric evaluation. Journal of Traumatic Stress, 28, 489-498. doi:10.1002/jts.22059

Bonanno, G. A., Galea, S., Bucciarelli, A., \& Vlahov, D. (2007). What predicts psychological resilience after disaster? The role of demographics, resources, and life stress. Journal of Consulting and Clinical Psychology, 75, 671-682. doi:10.1037/0022-006X.75.5.671

Brewin, C. R., Andrews, B., \& Valentine, J. D. (2000). Meta-analysis of risk factors for posttraumatic stress disorder in trauma-exposed adults. Journal of Counseling and Clinical Psychology, 68, 748-766.

Carey, K. B., Durney, S. E., Shepardson, R. L., \& Carey, M. P. (2015). Incapacitated and forcible rape of college women: Prevalence across the first year. Journal of Adolescent 
Health, 56(6), 678-680. doi:10.1016/j.jadohealth.2015.02.018

Carver, C. S. (1997). You want to measure coping but your protocol's too long: Consider the Brief COPE. International Journal of Behavioral Medicine, 4, 92-100. doi:10.1207/s15327558ijbm0401_6

Carver, C. S. (1998). Resilience and thriving: Issues, models, and linkages. Journal of Social Issues, 54, 245-266. doi:10.1111/0022-4537.641998064

Classen, C. C., Palesh, O. G., \& Aggarwal, R. (2005). Sexual Revictimization: A Review of the Empirical Literature. Trauma, Violence, \& Abuse, 6, 103-129.

Cole, A. S., \& Lynn, S. J. (2010). Adjustment of sexual assault survivors: Hardiness and acceptance coping in posttraumatic growth. Imagination, Cognition and Personality, 30(1), $111-127$.

Conley, A. H., Overstreet, C. M., Hawn, S. E., Kendler, K. S., Dick, D. M., \& Amstadter, A. B. (2017). Prevalence and predictors of sexual assault among a college sample. Journal of American College Health, 65(1), 41-49. doi:10.1080/07448481.2016.1235578

Connor, K. M., \& Davidson, J. R. (2003). Development of a new resilience scale: The ConnorDavidson Resilience Scale (CD-RISC). Depression and Anxiety, 18, 76-82. doi:10.1002/da.10113

Cutrona, C. E. \& Russell, D. (1987). The provisions of social relationships and adaptation to stress. In W. H. Jones \& D. Perlman (Eds.) Advances in personal relationships (Vol. 1, pp. 37-67). Greenwich, CT: JAI Press.

Dong, X., Li, G., Liu, C., Kong, L., Fang, Y., Kang, X., \& Li, P. (2017). The mediating role of resilience in the relationship between social support and posttraumatic growth among 
colorectal cancer survivors with permanent intestinal ostomies: A structural equation model analysis. European Journal of Oncology Nursing, 29, 47-52. doi:10.1016/j.ejon.2017.04.007

Dworkin, E. R., Menon, S. V., Bystrynski, J., \& Allen, N. E. (2017). Sexual assault victimization and psychopathology: A review and meta-analysis. Clinical Psychology Review, 56, 65-81. doi:10.1016/j.cpr.2017.06.002

Ehlers, A., \& Clark, D. M. (2000). A cognitive model of posttraumatic stress disorder. Behaviour Research and Therapy, 38(4), 319-345.

Evans, S. E., Steel, A. L., \& DiLillo, D. (2013). Child maltreatment severity and adult trauma symptoms: Does perceived social support play a buffering role? Child Abuse \& Neglect, 37(11), 934-943. doi:10.1016/j.chiabu.2013.03.005

Foa, E. B., \& Kozak, M. J. (1986). Emotional processing of fear: Exposure to corrective information. Psychological Bulletin, 99(1), 20-35.

Greene, R. R., Galambos, C., \& Lee, Y. (2003). Resilience theory: Theoretical and professional conceptualizations. Journal of Human Behavior in the Social Environment, 8, 75-91.

Gutner, C. A., Rizvi, S. L., Monson, C. M., \& Resick, P. A. (2006). Changes in coping strategies, relationship to the perpetrator, and posttraumatic distress in female crime victims. Journal of Traumatic Stress, 19, 813-823. doi:10.1003/jts.20158

Haden, S. C., Scarpa, A., Jones, R. T., \& Ollendick, T. H. (2007). Posttraumatic stress disorder symptoms and injury: The moderating role of perceived social support and coping for young adults. Personality and Individual Differences, 42(7), 1187-1198.

Hayes, A. (2012). PROCESS. www.afhayse.com

Hines, D. A., Armstrong, J. L., Reed, K. P., \& Cameron, A. Y. (2012). Gender differences in sexual assault victimization among college students. Violence and Victims, 27, 922-940. 
doi:10.1891/0886-6708.27.6.922

Hirai, M., Skidmore, S. T., Clum, G. A., \& Dolma, S. (2012). An investigation of the efficacy of online expressive writing for trauma-related psychological distress in Hispanic individuals. Behavior Therapy, 43, 812-824. doi:10.1016/j.beth.2012.04.006

Johnson, J. G., Cohen, P., Dohrenwend, B. P., Link, B. G., \& Brook, J. S. (1999). A longitudinal investigation of social causation and social selection processes involved in the association between socioeconomic status and psychiatric disorders. Journal of Abnormal Psychology, 108(3), 490-499. doi:10.1037/0021-843X.108.3.490

Jose, R., \& Novaco, R. W. (2016). Intimate partner violence victims seeking a temporary restraining order: Social support and resilience attenuating psychological distress. Journal of Interpersonal Violence, 31(20), 3352-3376. doi:10.1177/0886260515584352

Kaniasty, K., \& Norris, F. H. (2008). Longitudinal linkages between perceived social support and posttraumatic stress symptoms: Sequential roles of social causation and social selection. Journal of Traumatic Stress, 21, 274-281. doi:10.1002/jts.20334

Koss, M. P., Abbey, A., Campbell, R., Cook, S., Norris, J., Testa, M., White, J. (2007). Revising the SES: A collaborative process to improve assessment of sexual aggression and victimization. Psychology of Women Quarterly, 31, 357-370.

Leiner, A. S., Kearns, M. C., Jackson, J. L., Astin, M. C., \& Rothbaum, B. O. (2012). Avoidant coping and treatment outcome in rape-related posttraumatic stress disorder. Journal of Consulting and Clinical Psychology, 80, 317-321. doi:10.1037/a0026814

Littleton, H. L. (2010). The impact of social support and negative disclosure reactions on sexual assault victims: a cross-sectional and longitudinal investigation. Journal of Trauma \& Dissociation, 11, 210-227. doi:10.1080/15299730903502946 
Littleton, H., Horseley, S., John, S., \& Nelson, D. V. (2007). Trauma coping strategies and psychological distress: A meta-analysis. Journal of Traumatic Stress, 20, 977-988.

Luthar, S. S., Cicchetti, D., \& Becker, B. (2000). The construct of resilience: A critical evaluation and guidelines for future work. Child Development, 71(3), 543-562.

Marriott, C., Hamilton-Giachritsis, C., \& Harrop, C. (2014). Factors promoting resilience following childhood sexual abuse: A structured, narrative review of the literature. Child Abuse Review, 23, 17-34. doi:10.1002/car.2258

Ozer, E. J., Best, S. R., Lipsey, T. L., \& Weiss, D. S. (2003). Predictors of posttraumatic distress disorder and symptoms in adults: A meta analysis. Psychological Bulletin, 129, 52-73.

Roth, S., \& Cohen, L. J. (1986). Approach, avoidance, and coping with stress. American Psychologist, 41, 813-819. doi:10.1037/0003-066X.41.7.813

Schumm, J. A., Briggs-Phillips, M., \& Hobfoll, S. E. (2006). Cumulative interpersonal traumas and social support as risk and resiliency factors in predicting PTSD and depression among inner-city women. Journal of Traumatic Stress, 19, 825-836.

Scott, K. M., Koenen, K. C., King, A., Petukhova, M. V., Alonso, J., Bromet, E. J., ... Kessler, R. C. (2018). Post-traumatic stress disorder associated with sexual assault among women in the WHO World Mental Health Surveys. Psychological Medicine, 48(1), 155-167. doi:10.1017/S0033291717001593

Smith, H. L., Summers, B. J., Dillon, K. H., \& Cougle, J. R. (2016). Is worst-event trauma type related to PTSD symptom presentation and associated features? Journal of Anxiety Disorders, 38, 55-61. doi: 10.1016/j.janxdis.2016.01.007

Steine, I. M., Winje, D., Skogen, J. C., Krystal, J. H., Milde, A. M., Bjorvatn, B., \& ... Pallesen, S. (2017). Posttraumatic symptom profiles among adult survivors of childhood sexual abuse: 
A longitudinal study. Child Abuse \& Neglect, 67280-293. doi:10.1016/j.chiabu.2017.03.002

Stevens-Watkins, D., Sharma, S., Knighton, J. S., Oser, C. B., \& Leukefeld, C. G. (2014).

Examining cultural correlates of active coping among African American female trauma survivors. Psychological Trauma: Theory, Research, Practice, and Policy, 6(4), 328-336. doi: $10.1037 / \mathrm{a} 0034116$

Ullman, S. E., \& Peter-Hagene, L. (2014). Social reactions to sexual assault disclosure, coping, perceived control, and PTSD symptoms in sexual assault victims. Journal of Community Psychology, 42, 495-508. doi:10.1002/jcop.21624

Ullman, S. E., Townsend, S. M., Filipas, H. H., \& Starzynski, L. L. (2007). Structural models of the relations of assault severity, social support, avoidance coping, self-blame, and PTSD among sexual assault survivors. Psychology of Women Quarterly, 31, 23-37. doi:10.1111/j.1471-6402.2007.00328.x

van der Walt, L., Suliman, S., Martin, L., Lammers, K., \& Seedat, S. (2014). Resilience and post-traumatic stress disorder in the acute aftermath of rape: A comparative analysis of adolescents versus adults. Journal of Child \& Adolescent Mental Health, 26, 239-249. doi.org/10.2989/17280583.2014.923433

Wagner, A. C., Monson, C. M., \& Hart, T. L. (2016). Understanding social factors in the context of trauma: Implications for measurement and intervention. Journal of Aggression, Maltreatment \& Trauma, 25(8), 831-853. doi:10.1080/10926771.2016.1152341

Walsh, K., Blaustein, M., Knight, W. G., Spinazzola, J., \& van der Kolk, B. A. (2007). Resiliency Factors in the Relation Between Childhood Sexual Abuse and Adulthood Sexual Assault in College-Age Women. Journal of Child Sexual Abuse, 16, 1-17.

Weathers, F.W., Litz, B. T., Keane, T. M., Palmieri, P. A., Marx, B. P., \& Schnurr, P. P. (2013). 
The PTSD Checklist for DSM-5 (PCL-5). The National Center for PTSD:

Wilson, L. C., \& Scarpa, A. (2014). Childhood abuse, perceived social support, and posttraumatic stress symptoms: A moderation model. Psychological Trauma: Theory, Research, Practice, and Policy, 6(5), 512-518. doi:10.1037/a0032635

Wisco, B. E., Marx, B. P., Wolf, E. J., Miller, M. W., Southwick, S. M., \& Pietrzak, R. H. (2014). Posttraumatic stress disorder in the US veteran population: Results from the National Health and Resilience in Veterans Study. The Journal of Clinical Psychiatry, 75, 1338-1346. doi:10.4088/JCP.14m09328 
Table 2: Correlations for ASA only, CSA only, and SR Groups

\begin{tabular}{|c|c|c|c|c|c|c|c|c|c|c|}
\hline & 1 & 2 & 3 & 4 & 5 & 1 & 2 & 3 & 4 & 5 \\
\hline 1. $\quad$ SPS & & $.68^{* *}$ & $-.42^{* *}$ & .12 & $-.23^{* *}$ & & $.40^{* *}$ & $-.45^{* *}$ & .10 & $-.28^{*}$ \\
\hline 2. CD-RISC & $.46^{* *}$ & & $-.41^{* *}$ & .04 & $-.27^{* *}$ & & & $-.56^{* *}$ & -.06 & $-.48^{* *}$ \\
\hline 3. BCope-M & $-.35^{* *}$ & $-.35^{* *}$ & & $.22^{*}$ & $.69^{* *}$ & & & & $.43^{* *}$ & $.66^{* *}$ \\
\hline 4. BCope-A & .14 & $.34^{* *}$ & $.24^{* *}$ & & $.28^{* *}$ & & & & & $.46^{* *}$ \\
\hline 5. PCL-5 & $-.33^{* *}$ & $-.27^{* *}$ & $.65^{* *}$ & $.19^{*}$ & & & & & & \\
\hline
\end{tabular}

Note: ASA = Adult sexual assault; CSA = Childhood sexual abuse; $\mathrm{SR}=$ Sexually revictimized; SPS = Social

Provision Scale; BCope-M = Brief Cope Maladaptive; $B$ Cope-A= Brief Cope Adaptive; CD-RISC = Connor-

Davidson Resiliency Scale; PCL-5 = PTSD Checklist for DSM-5. Upper left= ASA Only; Lower left = CSA Only;

Upper right $=\mathrm{SR} ;{ }^{* *} p<.01 ;{ }^{*} p<.05$. 
Table 3. Relationships between Social Support and Posttraumatic Stress Symptom Severity Mediated by Resilience and Coping

\begin{tabular}{|c|c|c|c|c|c|c|c|c|c|c|c|c|c|}
\hline & \multirow[b]{4}{*}{ Predictors } & \multicolumn{3}{|c|}{ Criteria } & \multicolumn{9}{|c|}{ Indirect effects } \\
\hline & & \multirow{3}{*}{$\begin{array}{c}\text { CD-RISC } \\
\beta\end{array}$} & \multirow{3}{*}{$\begin{array}{c}\text { BC Maladaptive } \\
\beta \\
\beta\end{array}$} & \multirow{3}{*}{$\begin{array}{c}\text { PCL-5 } \\
\beta\end{array}$} & \multicolumn{3}{|c|}{ CD-RISC } & \multicolumn{3}{|c|}{ CD-RISC $\rightarrow$ BC Maladaptive } & \multicolumn{3}{|c|}{ BC Maladaptive } \\
\hline & & & & & \multicolumn{3}{|c|}{ Boot $95 \% \mathrm{CI}$} & \multirow[b]{2}{*}{$\beta$} & \multicolumn{2}{|c|}{ Boot $95 \%$ CI } & \multirow[b]{2}{*}{$\beta$} & \multicolumn{2}{|c|}{ Boot $95 \% \mathrm{CI}$} \\
\hline & & & & & $\beta$ & $L L$ & $U L$ & & $L L$ & $U L$ & & $L L$ & $U L$ \\
\hline \multirow{5}{*}{$\begin{array}{c}\text { ASA only } \\
(\mathrm{n}=106)\end{array}$} & SPS & $.66^{* *}$ & $-.26^{*}$ & .09 & & & & & & & & & \\
\hline & CD-RISC & - & -.24 & -.04 & & & & & & & & & \\
\hline & BC Maladaptive & - & - & $.70^{* *}$ & & & & & & & & & \\
\hline & Constant & .07 & .03 & .01 & & & & & & & & & \\
\hline & & $\mathrm{R}^{2}=.47^{* *}$ & $\mathrm{R}^{2}=21^{* *}$ & $\mathrm{R}^{2}=.48^{* *}$ & -.03 & -.19 & .15 & -.11 & -.25 & $<.01$ & -.18 & -.35 & -.02 \\
\hline \multirow{5}{*}{$\begin{array}{l}\text { CSA only } \\
(\mathrm{n}=97)\end{array}$} & SPS & $.46^{* *}$ & $-.24^{*}$ & -.11 & & & & & & & & & \\
\hline & CD-RISC & - & $-.23^{*}$ & -.02 & & & & & & & & & \\
\hline & BC Maladaptive & - & - & $.62^{* *}$ & & & & & & & & & \\
\hline & Constant & .02 & -.02 & $<-.01$ & & & & & & & & & \\
\hline & & $\mathrm{R}^{2}=.21^{* *}$ & $\mathrm{R}^{2}=.16^{* *}$ & $\mathrm{R}^{2}=.43^{* * *}$ & -.01 & -.09 & .07 & -.07 & -.15 & $<-.01$ & -.15 & -.29 & -.01 \\
\hline \multirow{9}{*}{$\begin{array}{c}\mathrm{SR} \\
(\mathrm{n}=52)\end{array}$} & SPS & $.41^{* *}$ & $-.28^{*}$ & .06 & & & & & & & & & \\
\hline & CD-RISC & - & $-.44^{* *}$ & -.17 & & & & & & & & & \\
\hline & BC Maladaptive & - & - & $.57^{* *}$ & & & & & & & & & \\
\hline & Constant & -.18 & -.10 & -.02 & & & & & & & & & \\
\hline & & $\mathrm{R}^{2}=.16^{* *}$ & $\mathrm{R}^{2}=.37^{* *}$ & $\mathrm{R}^{2}=.45^{* *}$ & -.07 & -.20 & .02 & -.10 & -.22 & -.03 & -.16 & -.41 & $<-.01$ \\
\hline & & & Criteria & & \multicolumn{9}{|c|}{ Indirect effects } \\
\hline & & CD-RISC & BC Adaptive & PCL-5 & \multicolumn{3}{|c|}{ CD-RISC } & \multirow{2}{*}{\multicolumn{3}{|c|}{ CD-RISC $\rightarrow$ BC Adaptive }} & \multicolumn{3}{|c|}{ BC Adaptive } \\
\hline & & & & & \multicolumn{3}{|c|}{ Boot $95 \%$ CI } & \multirow[b]{2}{*}{$\beta$} & & & & Boot & $5 \% \mathrm{CI}$ \\
\hline & & $\beta$ & $\beta$ & $\beta$ & $\beta$ & $L L$ & $U L$ & & $L L$ & $U L$ & $\beta$ & $L L$ & $U L$ \\
\hline ASA only & SPS & $.66^{* *}$ & .18 & -.15 & & & & & & & & & \\
\hline$(n=106)$ & CD-RISC & - & -.08 & -.18 & & & & & & & & & \\
\hline & BC Adaptive & - & - & $.31^{* *}$ & & & & & & & & & \\
\hline & Constant & .07 & .02 & .02 & & & & & & & & & \\
\hline & & $\mathrm{R}^{2}=.47^{* *}$ & $\mathrm{R}^{2}=.02$ & $\mathrm{R}^{2}=.17^{* *}$ & -.12 & -.32 & .06 & -.02 & -.08 & .04 & .05 & -.02 & .14 \\
\hline CSA only & SPS & $.46^{* *}$ & -.02 & $-.25^{*}$ & & & & & & & & & \\
\hline$(n=97)$ & CD-RISC & - & $.35^{* *}$ & $-.27^{*}$ & & & & & & & & & \\
\hline & BC Adaptive & - & - & $.32^{* *}$ & & & & & & & & & \\
\hline & Constant & .02 & -.01 & -.02 & & & & & & & & & \\
\hline & & $\mathrm{R}^{2}=.21^{* *}$ & $\mathrm{R}^{2}=.12^{* *}$ & $\mathrm{R}^{2}=.21^{* *}$ & -.12 & -.26 & -.02 & .05 & .01 & .11 & -.01 & -.08 & .07 \\
\hline & SPS & $.41^{* *}$ & .14 & -.17 & & & & & & & & & \\
\hline$(n=52)$ & CD-RISC & - & -.12 & $-.37^{* *}$ & & & & & & & & & \\
\hline & BC Adaptive & - & - & $.45^{* *}$ & & & & & & & & & \\
\hline & Constant & $\begin{array}{c}-.18 \\
\mathrm{P}^{2}-16^{* *}\end{array}$ & $\begin{array}{c}<.01 \\
\mathrm{R}^{2}-02\end{array}$ & $\begin{array}{c}-.08 \\
\mathrm{P}^{2}-44^{* *}\end{array}$ & & & & & & & & & \\
\hline & & $\mathrm{R}^{2}=.16^{* *}$ & $\mathrm{R}^{2}=.02$ & $\mathrm{R}^{2}=.44^{* *}$ & -.15 & -.33 & -.04 & -.02 & -.08 & .04 & .06 & -.09 & .22 \\
\hline
\end{tabular}

Note: ASA = Adult sexual assault; CSA = Childhood sexual abuse; SR = Sexually revictimized; SPS = Social Provision Scale; BC: Brief Cope CD-RISC = Connor-Davidson Resiliency Scale; PCL-5 = PTSD Checklist for DSM-5; LL = lower limit; UL = upper limit; ${ }^{* *} p<.01 ;{ }^{*} p<.05$. 


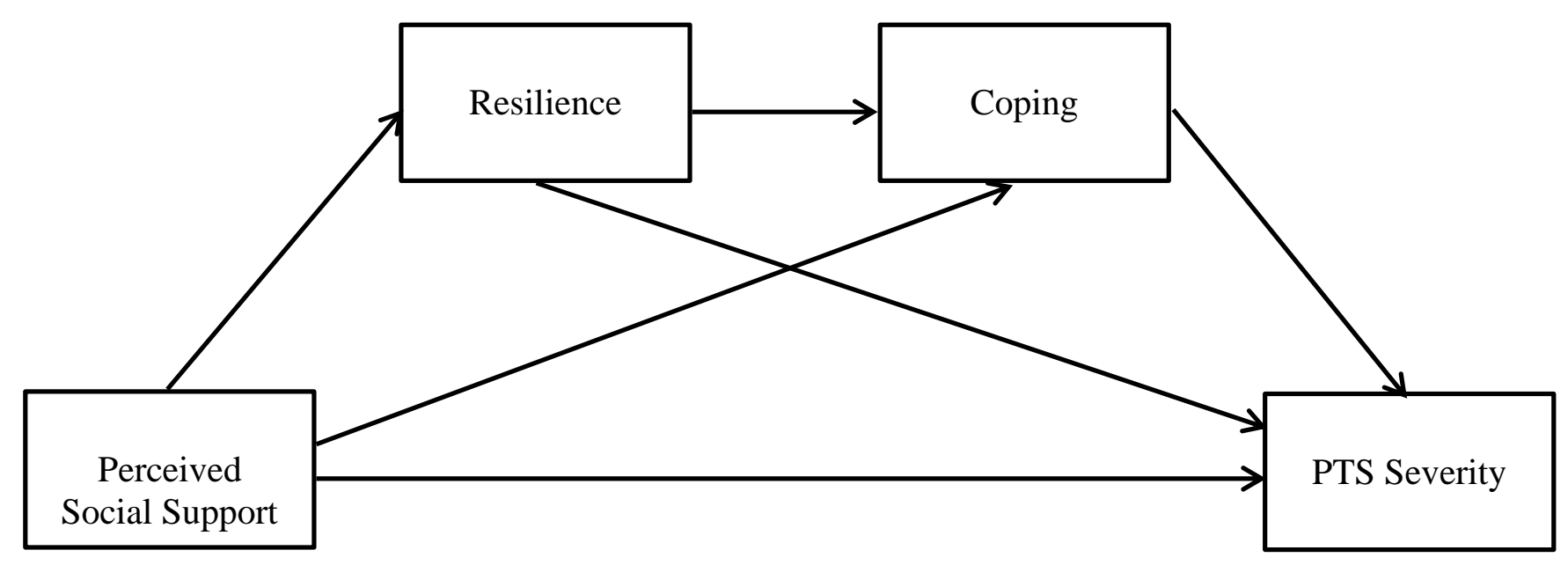

Figure 1: Hypothesized Model 
ASA Group

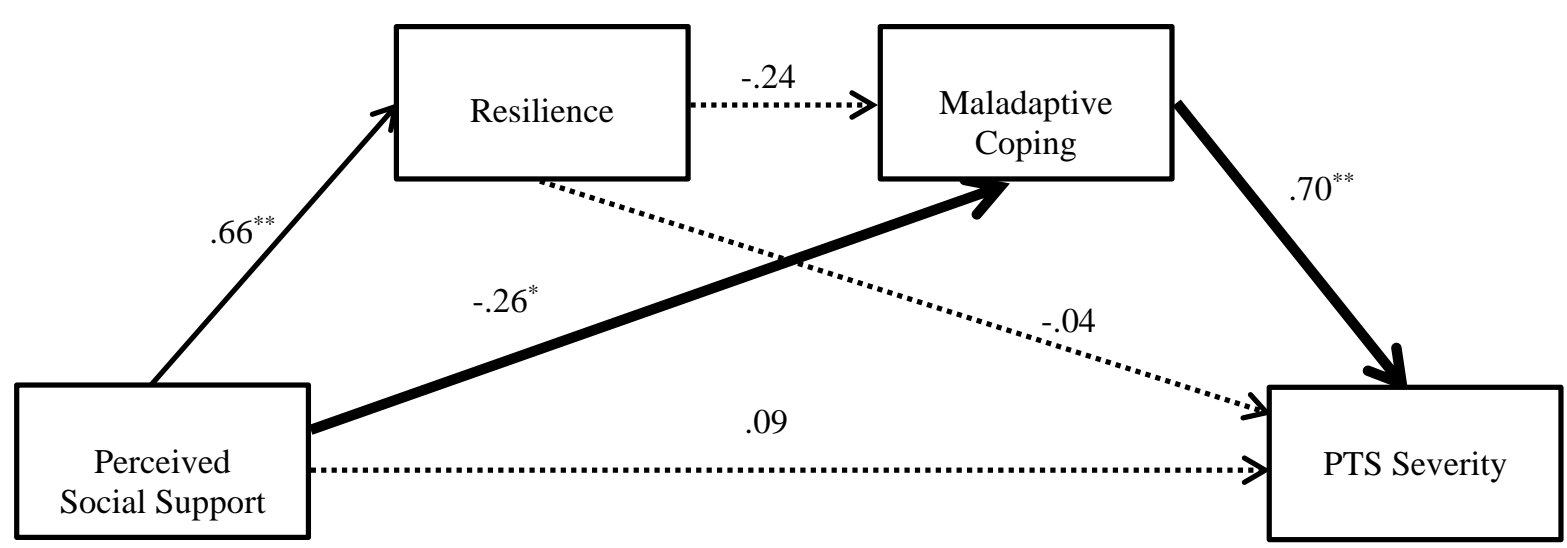

CSA Group

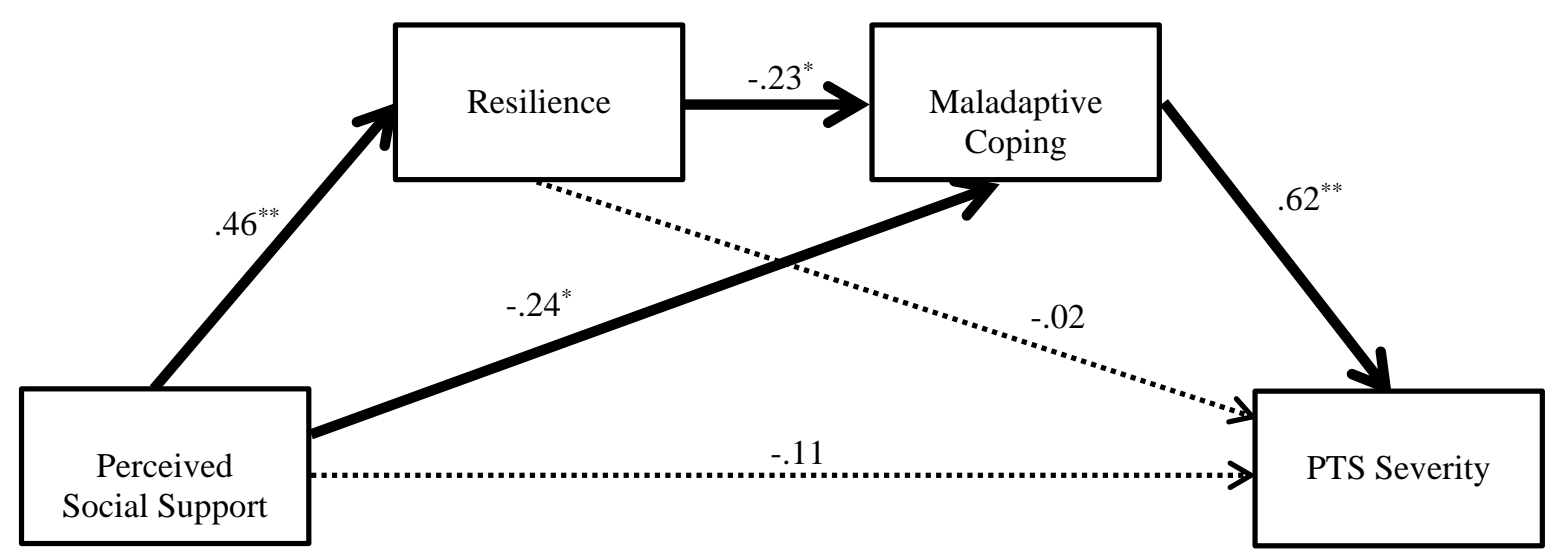

SR Group

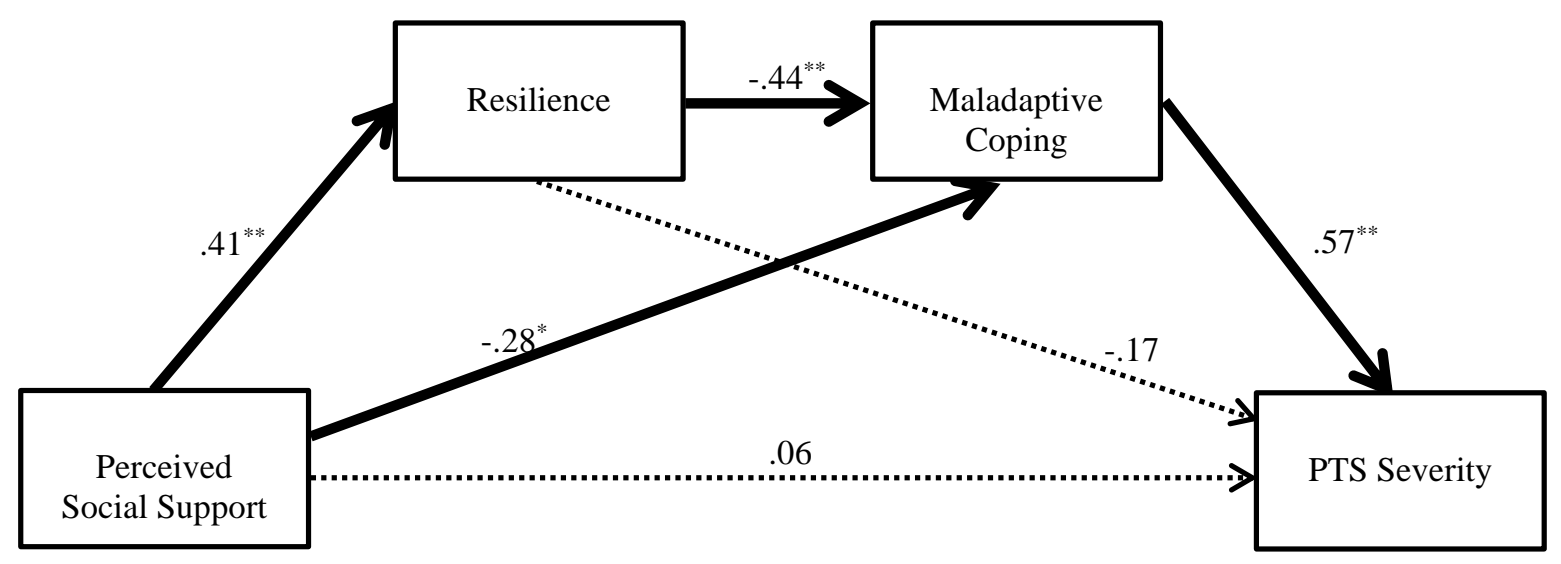

Figure 2: Relationships between Perceived Social Support and Posttraumatic Stress Symptom Severity Mediated by Resilience and Maladaptive Coping

Note: bold lines indicate significant indirect effects; dotted lines indicate non-significant paths 
ASA Group
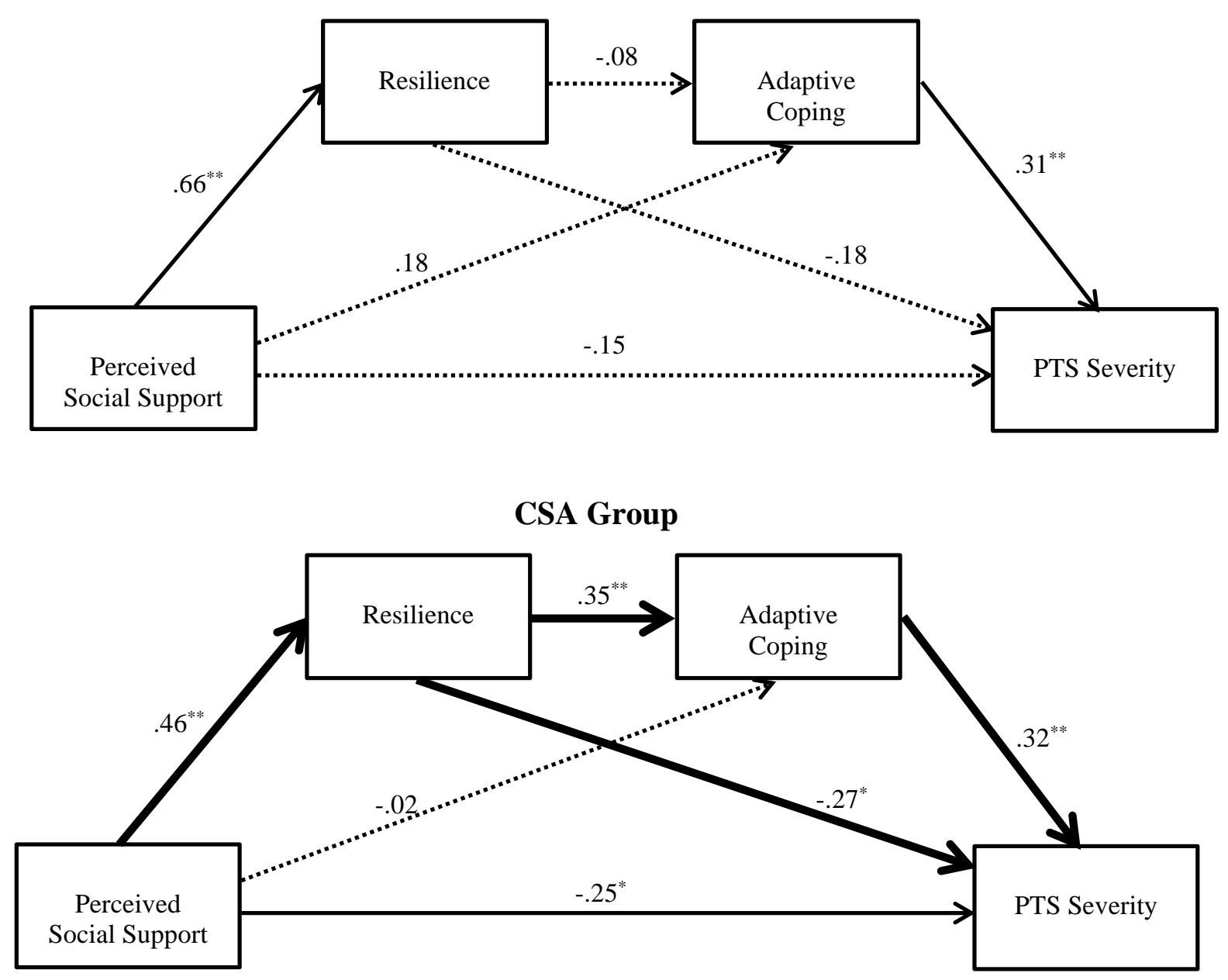

SR Group

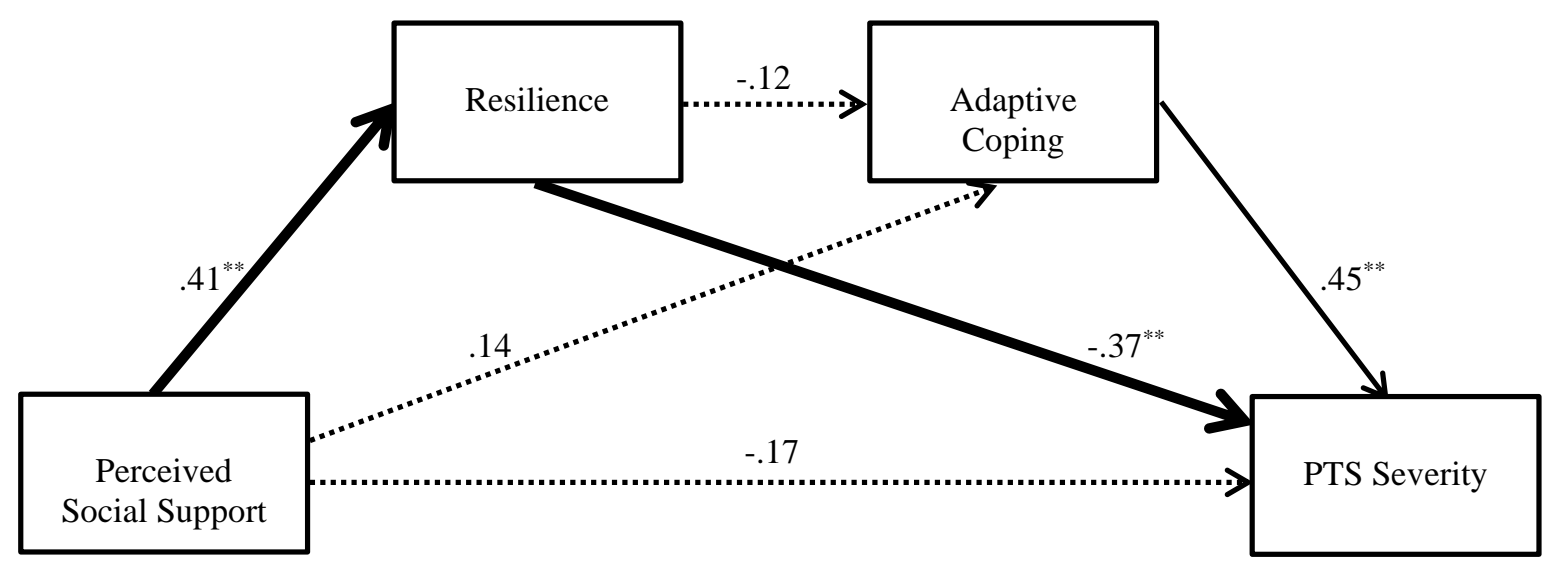

Figure 3: Relationships between Perceived Social Support and Posttraumatic Stress Symptom Severity Mediated by Resilience and Adaptive Coping

Note: bold lines indicate significant indirect effects; dotted lines indicate non-significant paths 


\section{AUTHOR BIOGRAPHIES}

Dr. Michiyo Hirai is an associate professor of psychological science at the University of Texas Rio Grande Valley. She earned her PhD in Clinical Psychology from Virginia Polytechnic Institute and State University. Her research focuses on etiology, assessment, and treatment of PTSD and anxiety disorders, emotion, cognition, and cross-cultural approaches to psychological issues.

Dr. Ruby Charak is an assistant professor of psychological science at the University of Texas Rio Grande Valley. She earned her PhD in Psychology from Vrije Universiteit (VU) Amsterdam, The Netherlands. Her research focuses on childhood maltreatment, PTSD, and structural equation modeling.

Dr. Laura Seligman is a professor of psychological science at the University of Texas Rio Grande Valley. She earned her PhD in Clinical Psychology from Virginia Polytechnic Institute and State University. Her research focuses on internalizing disorders in youth.

Dr. Joseph Hovey is a professor of psychological science at the University of Texas Rio Grande Valley. He earned his $\mathrm{PhD}$ in Clinical Psychology from the University of Michigan. His research focuses on anxiety disorders, culture and mental health, and suicide risk and protective factors. 
Dr. John Ruiz is an associate professor of psychology at the University of Arizona. He earned his PhD in Clinical Psychology from the University of Utah. His research focuses on psychosocial influences on health, psychological aspects of resilience in Latino health and health disparities.

Dr. Timothy Smith is a distinguished professor of psychology at the University of Utah. He earned his $\mathrm{PhD}$ in Clinical Psychology from the University of Kansas. His research focuses on personality and social risk factors for cardiovascular disease. 